To the Editor:

\title{
Nutritional status and productivity of Sri Lankan tea pluckers
}

I read with interest the above mentioned article, the conclusions of which are of great significance to the tea industry.

The researchers [1] have stated in their article that the study was carried out on Norwood Estate located at $2500 \mathrm{~m}$ above sea level. In fact, the highest elevation of Norwood estate is $1575 \mathrm{~m}$. The researchers have used an altitude adjusted cut-off value of $13.3 \mathrm{~g} / \mathrm{dL}$ to determine the prevalence of anaemia, which is based on the elevation of $2500 \mathrm{~m}$ above sea level. Using this cut-off value the prevalence of anaemia in non-pregnant estate women in the sample was calculated to be $94.4 \%$. This is high compared to the prevalence found by other studies. The most recent national survey, carried out by the Medical Research Institute [2] shows the prevalence of anaemia as $37.2 \%$ in non-pregnant women in the estate sector.

According to the WHO guide to programme managers [3] haemoglobin adjustment for an elevation of $1500 \mathrm{~m}$ is $0.5 \mathrm{~g} / \mathrm{dL}$. As such the factor for adjusting $\mathrm{Hb}$ values at the elevation of $1575 \mathrm{~m}$ is $0.5 \mathrm{~g} / \mathrm{dL}$ and the cutoff point for anaemia should be $12.5 \mathrm{~g} / \mathrm{dL}$, and not $13.3 \mathrm{~g} / \mathrm{dL}$. In their study [1] the blood samples were collected on filter paper and analysed in the University laboratory within a week. The method used should have been validated in the laboratory and the results included under methods. I feel that the authors should present the results using the correct cut-off point.

The study in question has been confined to only one estate from over 450 estates and cannot be generalised. In addition, the daily average tea leaves plucked per plucker depends on many factors such as the condition of the soil of the field, condition of the bushes, number of bushes per hectare, type of the tea plants (i.e. vegetative propagation or seedling), age of the tea bushes, weather, etc. As these agro-climatic conditions vary between fields, divisions, estates and districts, and contribute immensely to the productivity, the article should have indicated the measures taken as control for these variables.

\section{References}

1. Selvaratnam RR, de Silva LDR, Pathmeswaran A, de Silva NR. Nutritional status and productivity of Sri Lankan tea pluckers. Ceylon Medical Journal 2003; 48: 114-8.

2. Medical Research Institute. Assessment of Anaemia Status in Sri Lanka. Department of Health Services, 2001:56.

3. WHO. Iron deficiency Anaemia: Assessment, Prevention and Control. Geneva: World Health Organisation, 2001:99.

I Hettiarachchi, Director Health and Women's Programmes, Plantation Human Development Trust, Main Office, No. 427/14, Robert Gunawardena Mw. Battaramulla, Sri Lanka.

Correspondence: Tel: +94 11 2887500, Fax: +94 011 2888619, e-mail: <trustdh@lanka.ccom.lk>.

In reply:

To the Editor:

\section{Nutritional status and productivity of Sri Lankan tea pluckers}

We thank Dr. Hettiarachchi for pointing out that Norwood Estate is located at $1500 \mathrm{~m}$ and not $2500 \mathrm{~m}$, and that, therefore, the cut-off level for diagnosis of anaemia should be $12.5 \mathrm{~g} \mathrm{Hb} / \mathrm{dL}$ and not $13.3 \mathrm{~g} / \mathrm{dL}$. We re-calculated the prevalence of anaemia using this cut-off, and find that it decreased from $94.4 \%$ to $84.2 \%$. This is still a very high rate, and so our conclusion that 'most of the study population had chronic energy deficiency and anaemia' must remain unaltered. The method we used for estimating haemoglobin levels has been validated and recommended for use by the US National Committee for Clinical Laboratory Standards [1].

We agree with Dr. Hettiarachchi that agro-climatic conditions may vary greatly between fields, divisions, estates, etc, and that these factors could contribute im- mensely to productivity in general. In fact, as shown in Table 1 of our paper, we did find that average productivity varied between the five divisions included in our study [2]. Because of this, the multiple regression analyses were adjusted for estate division. This is stated quite clearly in the penultimate paragraph of the methods section in our paper.

We also wish to point out that the multiple regression was carried out using absolute $\mathrm{Hb}$ values. Thus our primary conclusion that 'productivity was strongly associated with the degree of anaemia' also remains unaffected by the altitude correction.

\section{References}

1. National Committee for Clinical Laboratory Standards. Reference and selected procedures for the quantitative 


\section{Correspondence}

determination of haemoglobin in blood (Approved standard C12-A). 2nd edn. Wayne PA, NCCLS, 1994.
2. Selvaratnam RR, de Silva LDR, Pathmeswaran A, de Silva NR. Nutritional status and productivity of Sri Lankan tea pluckers. Ceylon Medical Journal 2003; 48: 114-8.

LDR de Silva, Senior Lecturer, Department of Biochemistry \& Clinical Chemistry, A Pathmeswaran, Senior Lecturer, Department of Community \& Family Medicine, and NR de Silva, Professor, Department of Parasitology, Faculty of Medicine, University of Kelaniya, Sri Lanka. 